\title{
Flooding overshadows phosphorus availability in controlling the intensity of arbuscular mycorrhizal colonization in Sangyod Muang Phatthalung lowland indica rice
}

\author{
Lompong Klinnawee ${ }^{\mathrm{a}, *}$, Nuttapol Noirungsee ${ }^{\mathrm{b}, \mathrm{c}}$, Khachonphong Nopphakat ${ }^{\mathrm{a}}$, \\ Phanthipha Runsaeng ${ }^{\mathrm{d}}$, Thanin Chantarachot ${ }^{\mathrm{e}}$ \\ a Division of Biological Science, Faculty of Science, Prince of Songkla University, Songkhla 90110 Thailand \\ b Department of Biology, Faculty of Science, Chiang Mai University, Chiang Mai 50200 Thailand \\ c Research Center in Bioresources for Agriculture, Industry and Medicine, Chiang Mai University, Chiang \\ Mai 50200 Thailand \\ ${ }^{d}$ Division of Health and Applied Sciences, Faculty of Science, Prince of Songkla University, Songkhla \\ 90110 Thailand \\ e Center of Excellence in Environment and Plant Physiology, Department of Botany, Faculty of Science, \\ Chulalongkorn University, Bangkok 10330 Thailand
}

*Corresponding author, e-mail: lompong.k@psu.ac.th

Received 4 Nov 2020

Accepted 29 Jan 2021

\begin{abstract}
Phosphorus (P) availability and soil water are two important environmental factors in lowland rice paddies. They limit the ability of rice to form mutualistic associations with arbuscular mycorrhizal fungi (AMF). The dynamics of this symbiotic interaction are intensified by phosphorus deficiency and attenuated by anaerobic conditions. However, the effects of combined phosphorus deficiency and anaerobic conditions on AMF symbiosis in paddy soil were unproven. The main objective of this study is to determine the influence of phosphorus and water availabilities on indigenous AMF colonization and community in Sangyod Muang Phatthalung (SMP) rice. Rice seedlings were grown in pots containing P-deficient organic paddy soil with or without phosphorus fertilization under non-flooded and flooded conditions for 2, 4 and 6 weeks. The application and omission of P soil fertilization influenced phosphate accumulations in rice seedlings, producing conditions of P-sufficiency and P-deficiency, respectively, in the plants. To determine the effects of phosphorus and water availabilities on AMF colonization and community structures, roots were analyzed microscopically and molecularly. Flooding considerably reduced the intensity of indigenous AMF root colonization whereas the nonenrichment of P availability did not. Reduced AMF colonization was concomitant with lower abundances of two major Glomeromycota ASVs in roots under flooding. This result suggested that soil water availability plays the primary role in shaping AMF communities in SMP roots. This study emphasized the primacy of water management when considering the use of AMF in the production of SMP rice in an organic cultivation system.
\end{abstract}

KEYWORDS: arbuscular mycorrhizal fungi, phosphorus availability, flooded condition, Sangyod Muang Phatthalung rice, lowland indica rice

\section{INTRODUCTION}

In various agro-ecosystems, phosphorus (P) deficiency in the soil is one of the major constraints limiting plant growth and productivity. To overcome this problem, most land plants establish mutualistic associations with arbuscular mycorrhizal fungi (AMF). This symbiotic relationship enables host plants to accumulate more P, especially in shoots, via the mycorrhizal $\mathrm{P}$ uptake pathway in roots [1]. In return, the host plants reward AMF with photosyn- thates such as carbohydrates and lipids [2]. However, the plant-AMF symbiosis is dynamically finetuned by environmental $P$ availability. The degree of AMF colonization varies inversely with the available $P$ levels in the rhizosphere $[3,4]$, indicating that $P$ availability is an essential factor in the regulation of the AMF symbiosis.

Apart from soil $\mathrm{P}$ levels, gravimetric water regimes also regulate plant-AMF symbiosis. The intensity of AMF colonization in roots is typically inhibited by flooding [5]. In wetland ecosystems, 
for example, the duration of flooding and underground water levels limit indigenous AMF colonization and strongly affect AMF communities in host plants $[6,7]$. Although AMF symbiosis can exist in wetland plant species [8], it seems likely that anoxic or hypoxic conditions as a result of flooding are unfavorable to AMF. In paddies of lowland rice (Oryza sativa L.), for instance, the natural colonization rate in roots is in the mere range of 0 to 40 percent, depending on the growth and developmental stage of the plant $[9,10]$. Even though AMF colonization in lowland rice roots is impeded by flooding, the remaining AMF in the roots is usually sufficient to maintain the mycorrhizal $\mathrm{P}$ uptake pathway [5]. The presence of AMF in lowland rice paddies improves $\mathrm{P}$ uptake in roots by increasing $\mathrm{P}$ mineralization in the rhizosphere [11]. Furthermore, these fungi also ameliorated $\mathrm{P}$ losses in rice paddies by preventing leaching and runoff of $\mathrm{P}$ from the soil [12].

In Thailand, the practice of organic rice farming is increasing progressively, in part thanks to its promotion by the Thai government [13]. Typically, only green manure and biofertilizer are applied on organic rice paddies to improve the soil [14]. To maximize soil nutrients, especially $\mathrm{P}$, the application of AMF can potentially be integrated. Therefore, an understanding of AMF symbiosis in lowland rice paddies is fundamental for organic farming management.

AMF are ubiquitously found in lowland rice paddies. However, compared to AMF communities in upland rice fields, lowland communities are highly influenced by water availability. Flooding in lowland rice paddies reduces AMF abundance, species richness and species diversity in rice roots [15]. The population of AMF in most genera is generally depleted in this type of agro-ecosystem [15]. Acaulospora was found to be the dominant AMF genus in lowland rice paddies [16]. In Thailand, the AMF genera Glomus and Acaulospora in rice paddies have been reported [10].

In rice, as in other species, $\mathrm{P}$ deficiency and flooding have opposing impacts on AMF symbiosis $[4,5]$. A study on the colonization of Glomus mosseae and Glomus intraradices in the rice cultivar Shafagh from northern Iran under different $\mathrm{P}$ and flooding regimes showed that both flooding and $\mathrm{P}$ supplementation in soil additively inhibit AMF colonization [11]. However, as rice-AMF symbiosis can be specific to the conditions and genotypes of both rice and AMF under the study, it is not known how flooding and $\mathrm{P}$ availability affect the rates and com- munity dynamics of AMF colonization in Thai rice in natural lowland paddy soil. In this study, we investigated the interaction between P deficiency and soil flooding on rice-AMF symbiosis in P-deficient organic paddy soil. AMF colonization and changes in the indigenous AMF communities were determined in seedlings of Sangyod Muang Phatthalung (SMP) rice grown in the soil with or without $P$ fertilization under different water regimes. Our data demonstrated that soil water availability plays a primary role in shaping the landscape of AMF communities in rice roots as flooding reduced AMF colonization regardless of soil $\mathrm{P}$ availability. This emphasizes that water management should be prioritized when the use of AMF is considered for rice production in an organic lowland cultivation system.

\section{MATERIALS AND METHODS}

\section{Soil sampling and analyses}

The soil used in this study was obtained from organic rice paddies of the Phatthalung Rice Research Center, Phatthalung, Thailand. For physical property analysis, bulk soil was collected from 3 different sites $(n=3)$. Soil organic matter was determined by the titration method. Total $\mathrm{N}$ was determined by combustion using a $\mathrm{C} / \mathrm{N}$ analyzer CN628 (LECO, Thailand) [17]. Total P and available $\mathrm{P}$ were extracted from soil samples using a nitric-perchloric solution in a 1:1 ratio and water, respectively. The amount of $\mathrm{P}$ was determined by the molybdovanadophosphate method using the Prove 300 spectrophotometer (Merck KGaA, Germany) [17]. Total potassium was determined by the flame photometric method using inductively coupled plasma-optical emission spectrometry (ICPOES, Avio 500, Perkin Elmer, USA) [17]. Soil pH and electroconductivity were measured by a conductivity meter (Orion Star A112, Thermo Fisher Scientific, Thailand) [17].

\section{Plant materials}

SMP is an elite indica rice variety grown in Phatthalung province in Southern Thailand with a protected geographical indication status. The unique geographical origin of the rice variety was a reason for its selection as a model for the interaction of rice with the indigenous AMF in a lowland agroecosystem of Southern Thailand. The pot experiment was set up in an open greenhouse during May to July 2019. The temperature and relative humidity, recorded by a data logger $\left(\mathrm{HOBO}^{\circledR}\right.$ Pro v2, USA), ranged from $25-35^{\circ} \mathrm{C}$ and $50-90 \%$, respec- 
tively. Seeds were sown in pots containing $1.5 \mathrm{~kg}$ of organic paddy soil. The seedlings were watered 3 times a week with $150 \mathrm{ml}$ of distilled water and fertilized once a week with $150 \mathrm{ml}$ of P-added $(10 \mathrm{mg} / \mathrm{l} \mathrm{P})$ or no P $(0 \mathrm{mg} / \mathrm{l} \mathrm{P})$ Yoshida solution. Flooding treatment of seedlings commenced after 2 weeks. To recreate flooded conditions, pots with sealed drainage holes were flooded with enough distilled water to produce $2-\mathrm{cm}$ of standing water above the soil. An equal amount of distilled water was applied to pots with open drainage holes to create the non-flooded control conditions. In all, the experiment comprised 4 different growing conditions: high $\mathrm{P} /$ non-flooded, low $\mathrm{P} /$ non-flooded, high $\mathrm{P} /$ flooded and low $\mathrm{P} /$ flooded. Each condition was applied to 6 biological replicates $(n=6)$, each of which contained 6 seedlings. The seedlings were subsequently grown in an open greenhouse for 2 , 4 and 6 weeks. At each time point, tissues were harvested, and shoot and root fresh weights were recorded before storing the tissues at $-80^{\circ} \mathrm{C}$.

\section{Measurement of soluble inorganic P contents in rice tissues}

Soluble inorganic P (Pi) content was measured using ferrous sulfate-ammonium molybdate reagent [18]. Samples were taken from the pool of homogenized leaf or root tissues of 6 individual plants. Aliquots of $20 \mathrm{mg}$ of leaf tissue and $40 \mathrm{mg}$ of root tissue were digested in $600 \mu \mathrm{l}$ of $3 \%(\mathrm{v} / \mathrm{v})$ perchloric acid. After centrifugation at $11000 \mathrm{rpm}$ for $5 \mathrm{~min}$, the supernatant was collected and then mixed with $400 \mu \mathrm{l}$ of the assay reagent containing $1 \%(\mathrm{w} / \mathrm{v})\left(\mathrm{NH}_{4}\right)_{6} \mathrm{Mo}_{7} \mathrm{O}_{24} \cdot 4 \mathrm{H}_{2} \mathrm{O}$ and $5 \%(\mathrm{w} / \mathrm{v})$ $\mathrm{FeSO}_{4} \cdot 7 \mathrm{H}_{2} \mathrm{O}$ in $1 \mathrm{~N} \mathrm{H}_{2} \mathrm{SO}_{4}$. After shaking followed by incubation for $10 \mathrm{~min}$, absorption at $720 \mathrm{~nm}$ was measured using a microplate reader (BIOTEX PowerwaveX). The Pi content in each sample was calculated using a $\mathrm{KH}_{2} \mathrm{PO}_{4}$ (5-250 nmole range) standard.

\section{Measurement of AMF root length colonization}

Rice roots were cut into $1.5 \mathrm{~cm}$ sections, washed with water and cleaned in $10 \%(\mathrm{w} / \mathrm{v}) \mathrm{KOH}$ at $95^{\circ} \mathrm{C}$ for $15 \mathrm{~min}$. The tissues were subsequently rinsed with deionized water and then incubated in $1 \%(\mathrm{v} / \mathrm{v}) \mathrm{HCl}$ at room temperature for $10 \mathrm{~min}$. The $\mathrm{HCl}$ solution was replaced with $1 \mathrm{ml}$ of Trypan blue staining solution made up of $0.05 \%$ (w/v) Trypan blue, 30\% (v/v) lactic acid and 30\% (v/v) glycerol. The root samples were de-stained overnight with $50 \%(\mathrm{v} / \mathrm{v})$ glycerol. Approximately 15 root sections from each replicate were mounted on a microscope slide with 50\% (v/v) glycerol. The slide was sealed with transparent nail polish and observed under a light microscope (100 views per slide) using $10 \times$ magnification to quantify AMF root length colonization.

\section{Genomic DNA preparation}

Rice root tissue for DNA analysis was collected by pooling roots from the same pot. Root tissues were washed 3 times in a $15 \mathrm{ml}$ tube containing $5 \mathrm{ml}$ sterile PBS buffer [130 mM NaCl, $7 \mathrm{mM} \mathrm{Na}_{2} \mathrm{HPO}_{4}$, $3 \mathrm{mM} \mathrm{NaH}_{2} \mathrm{PO}_{4}, 0.02 \%$ (v/v) Silwet L-77, $\mathrm{pH} 7.0$ ] and then shaken for $20 \mathrm{~min}$ at $180 \mathrm{rpm}$. The cleaned roots were dried, immediately frozen in liquid nitrogen and stored at $-80^{\circ} \mathrm{C}$. Frozen tissues were pulverized, and an aliquot of $100 \mathrm{mg}$ was used for genomic DNA isolation using a plant DNA minipreparation method with some modifications [19].

\section{Fungal community analysis}

Paired-end amplicon sequencing of the internal transcribed spacer 2 (ITS2) was performed at Novogene (Korea) on the Illumina MiSeq platform using the ITS5-1737F (5'-GGAAGTAAAAGTCG TAACAAGG-3') and ITS2-2043R (5'-GCTGCGTTC TTCATCGATGC-3') primers. Amplicon sequence variants (ASVs) were obtained by processing sequences with DADA2 [20] implemented in QIIME2 (2018.4 Release) [21]. Fungal taxonomy was assigned to the ASVs using the Naive-Bayes classifier trained on the UNITE database (version 7.2) [22]. The sequences were imported into the Phyloseq package [23] in $\mathrm{R}$ for further processing. The relative abundances of Glomeromycota sequence variants in all samples were obtained by dividing each ASV by the total number of sequences assigned to the phylum Glomeromycota. The sequences were rarefied at 50000 sequences per sample, in which the rarefaction curves were constant. The number of observed species, evenness, Shannon index and Bray-Curtis index were calculated using Phyloseq. Permutational multivariate analysis of variance (PERMANOVA) was carried out with 999 permutations using the Vegan package [24]. Differential abundance analysis was performed with DESeq2 [25] as implemented in the Phyloseq package. The data were visualized with ggplot2 [26]. Finally, ASVs belonging to Glomeromycota were blasted on the UNITE species hypothesis database to achieve greater taxonomic detail [22]. Sequences from this study were made available through the 
European Nucleotide Archive under project code PRJEB41021(ERP124744).

\section{Statistical analyses}

Means of shoot and root fresh weight, shoot and root Pi concentration, root length colonization under different water statuses, $\mathrm{P}$ availabilities and weeks were compared by three-way ANOVA following Least Significant Difference (LSD) using the agricolae package [27] in the statistical software $\mathrm{R}$ (version 3.6.3).

\section{RESULTS}

\section{Application of $P$ in paddy soil increases internal} $\mathrm{Pi}$ accumulation in rice seedlings

Bulk soil from organic rice paddies was collected to set up the greenhouse experiment. The soil compositions included dense rice roots from the previous cycle of rice cultivation (Fig. S1). The soil contained $1.75 \%(\mathrm{w} / \mathrm{w})$ organic matter, $0.06 \%(\mathrm{w} / \mathrm{w})$ total $\mathrm{N}$,
$0.008 \%(\mathrm{w} / \mathrm{w})$ total P and $0.21 \%(\mathrm{w} / \mathrm{w})$ total K. Soil $\mathrm{pH}$ and conductivity were 5.18 and $0.14(\mathrm{ds} / \mathrm{m})$, respectively. However, no available P was detected. Therefore, the soil used in this study was considered P-deficient.

In this experiment, SMP seedlings were grown in P-deficient paddy soil with or without added P. These conditions were denoted high $\mathrm{P}$ and low $\mathrm{P}$, respectively. Two-week-old seedlings grown under both conditions were subjected to flooding treatment. Changes in shoot and root Pi contents were measured after 2, 4 and 6 weeks. The results showed that $\mathrm{P}$ availability, soil flooding and culture duration had an influence on Pi accumulations in shoots and roots (Table S1). Increases in shoot Pi contents were greater in the rice seedlings grown in high $\mathrm{P}$ conditions than in those grown in low $\mathrm{P}$ conditions, especially after 4 weeks (Fig. 1A). Changes in root Pi contents, however, were generally unaffected by P fertilization (Fig. 1B). Concomitant to the Pi contents, shoot fresh weight was significantly
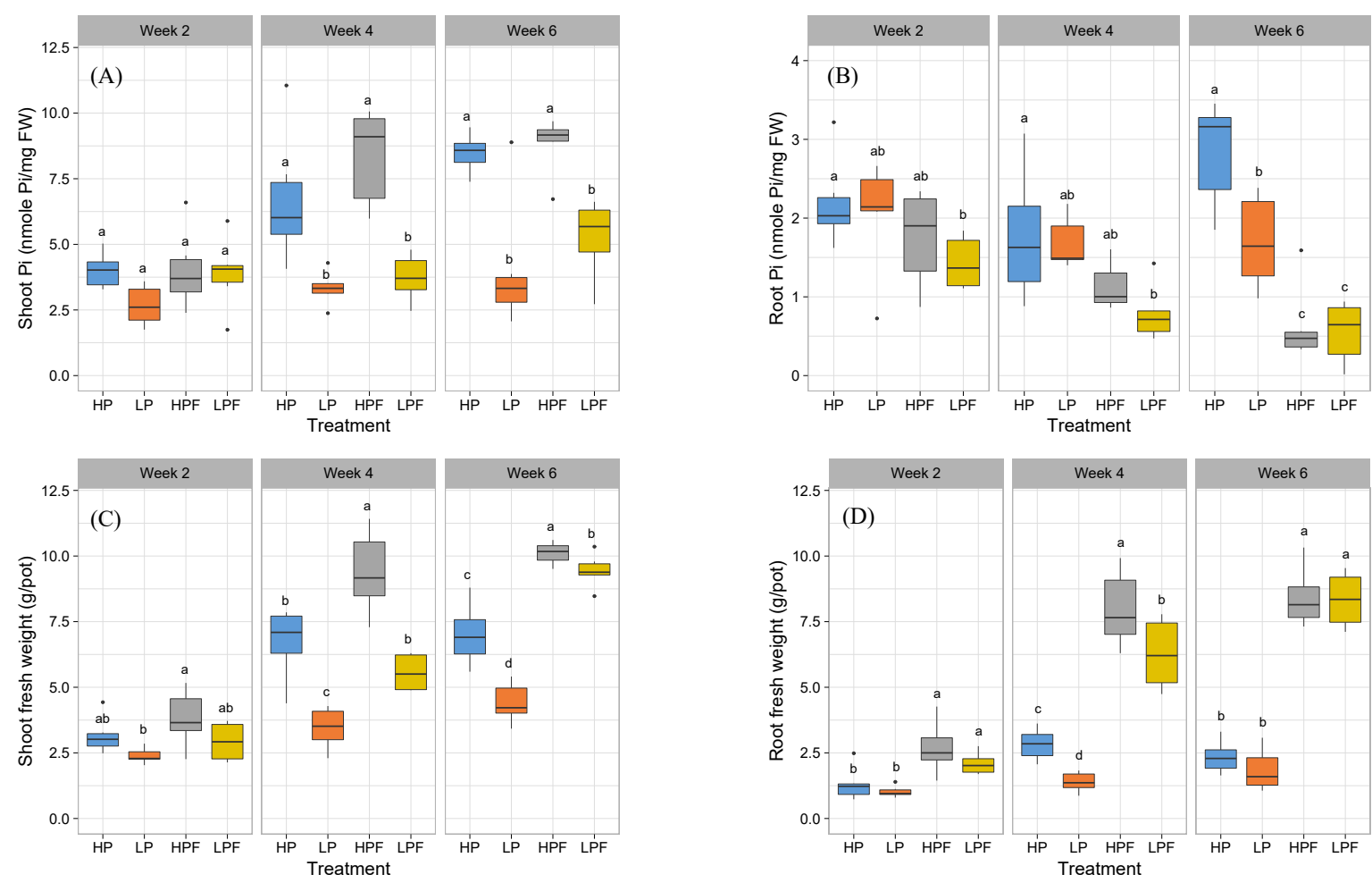

Fig. 1 Effect of $\mathrm{P}$ application on internal Pi levels in rice seedlings under non-flooded and flooded conditions. Rice seedlings were grown for 2, 4 and 6 weeks under 4 different $P$ and water regimes: high $P$ with non-flooding (HP), low $P$ with non-flooding (LP), high P with flooding (HPF) and low P with flooding (LPF). The box plots show the distribution of (A) shoot Pi content, (B) root Pi content, (C) shoot fresh weight and (D) root fresh weight ( $n=6$ biological replicates). Statistical analysis was performed by three-way ANOVA following LSD. Different letters within the same time point indicate significant differences $(p<0.05)$. 
greater in rice seedlings fertilized with P (Fig. 1C and Fig. S2) whereas root fresh weight was mostly unaffected by P fertilization (Fig. 1D). Regardless of the amount of available $\mathrm{P}$ in the soil, flooding resulted in a significant increase in shoot and root fresh weights compared to the control non-flooded conditions (Fig. 1C,1D). Additionally, increases in shoot and root fresh weights as a result of flooding were more apparent when seedlings were grown in high $\mathrm{P}$ conditions, while the effects of flooding on $\mathrm{Pi}$ accumulation were negligible in both shoot and root tissues (Fig. 1C,1D). Together, these results confirmed that the application of $\mathrm{P}$ increases the accumulation of $\mathrm{Pi}$ in rice seedlings grown in $\mathrm{P}$ deficient lowland paddy soil and that this effect is independent of soil water.

\section{Flooding but not internal P status limits mycorrhizal colonization in lowland rice}

The observation that the application of P similarly influenced the $\mathrm{Pi}$ content in rice seedlings grown in both non-flooded and flooded conditions led us to hypothesize that flooding might inhibit mycorrhizal colonization of rice roots even though the rice seedlings are P-deficient. To test whether the mycorrhization rate in rice roots is influenced by soil $\mathrm{P}$ availability and water regime, root length colonization was investigated in rice seedlings grown under the 4 different conditions (Fig. 2A,2B). The results indicated that water status and culture duration affected AMF colonization (Table S1). While $\mathrm{P}$ application had minimal effect, flooding strongly inhibited AMF colonization (Fig. 2C). In flooded conditions, root length colonization was highest in the first 2 weeks and progressively decreased over the cultivation period. Nevertheless, AMF colonization was still detected in the flooded condition after 4 and 6 weeks (Fig. 2C). We further speculated that flooding not only reduced the intensity of AMF colonization but might also affect fungal and AMF communities in the rice roots. Therefore, ITS2sequencing was performed to determine the effect of $\mathrm{P}$ and water availability on fungal and AMF communities in the rice roots.

\section{Flooding alters fungal communities in rice roots}

Due to the considerable reduction of AMF colonization observed in roots at the 4th week after flooding, we used these samples to investigate the effects of $P$ and water availability on fungal and AMF communities. Species evenness, species richness and Shannon diversity indices in the rice roots were similar under all 4 conditions (Fig. 3A). However,

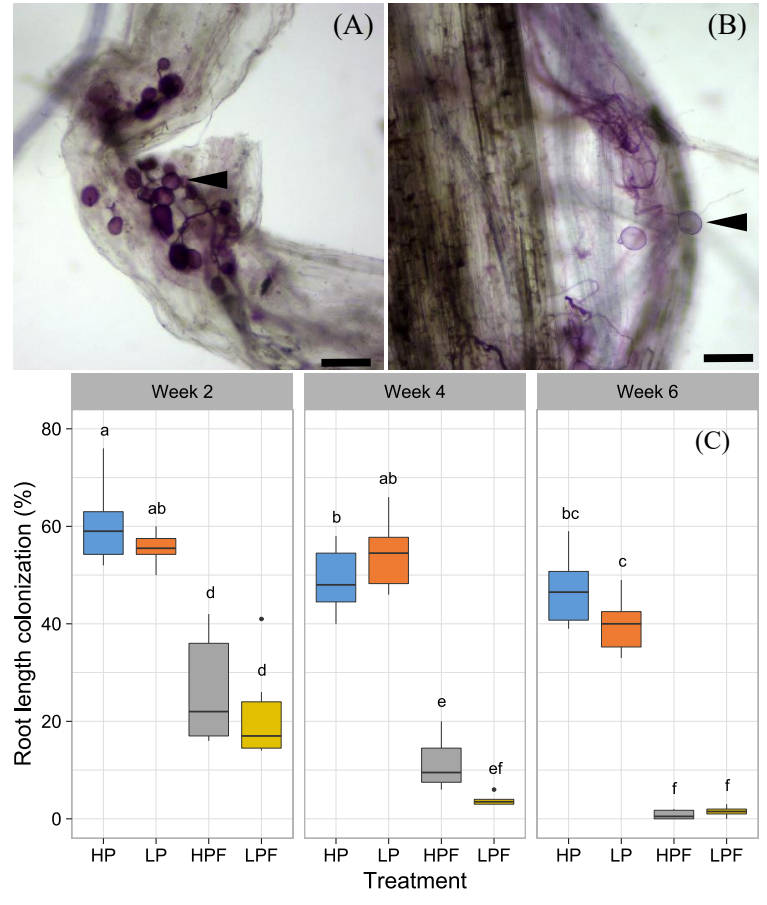

Fig. 2 Mycorrhizal root length colonization in rice roots at 2, 4 and 6 weeks after treatment. (A, B) Mycorrhizal colonization in rice roots was observed under light microscope (100 views, $10 \times$ objective magnification, scale $=$ $200 \mu \mathrm{m}$ ); arrow heads indicate AMF spores attached to rice roots. The colonization rates at different time points were compared between all treatments. (C) The box plots show the distribution of percent root length colonization in high $\mathrm{P}$ with non-flooding (HP), low $\mathrm{P}$ with non-flooding (LP), high $\mathrm{P}$ with flooding (HPF) and low $\mathrm{P}$ with flooding (LPF) conditions ( $n=6$ biological replicates). Statistical analysis was performed by three-way ANOVA following LSD. Different letters indicate significant differences $(p<$ 0.05).

analysis of beta diversity indicated that the fungal communities in non-flooded and flooded conditions were different (Fig. 3B and Table S2). These data suggested that flooding affected the fungal community in the rice roots.

Among all the fungal ASVs in the roots, there were 8 ASVs of Glomeromycota (GlomASVs) (Fig. 4). $75 \%$ of the AMF sequences belonged to ASV2 (55.7\%) and ASV4 (20.0\%), which were the major GlomASVs returned from blasting to the UNITE database. All 8 GlomASVs shared sequence similarities in the range of $94.8-100 \%$ with the fungal ITS sequences in the family Glomeraceae. Moreover, GlomASV1 and GlomASV7 were hypothetically identified as Rhizophagus clarus at 100.0 

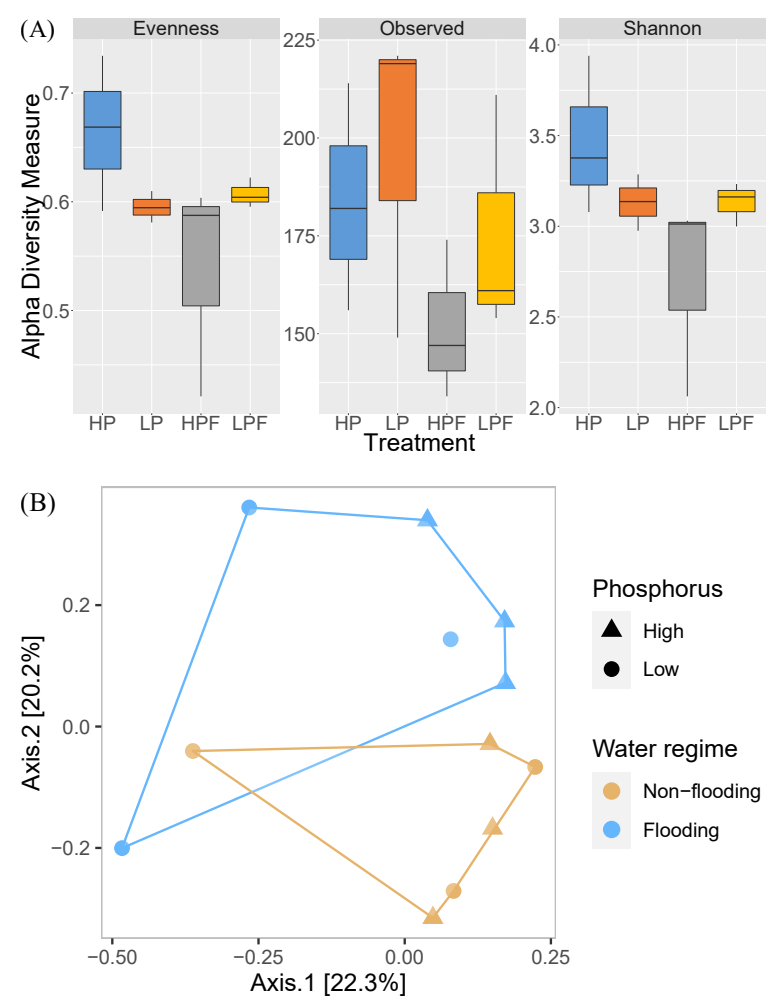

Fig. 3 Fungal community in the rice roots under the 4 different conditions.(A) Alpha diversity and (B) principal coordinate analysis (PCOA) of ITS sequences using BrayCurtis distance. In (A): HP, high P with non-flooding; LP, low $\mathrm{P}$ with non-flooding; HPF, high $\mathrm{P}$ with flooding; and LPF, low P with flooding.

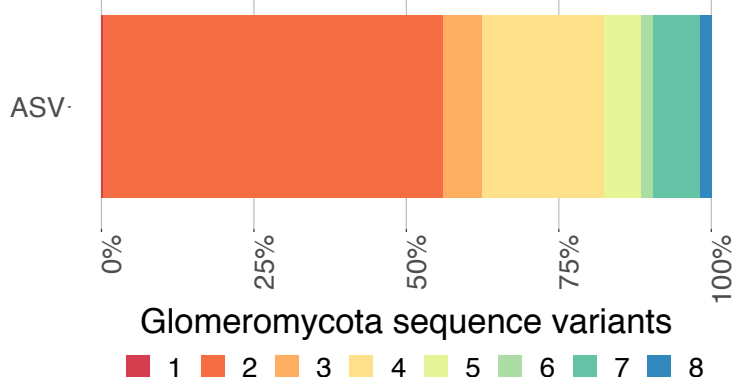

Fig. 4 Proportional distributions of amplicon sequence variants (ASVs) belonging to Glomeromycota in all samples. The 8 GlomASVs shared high sequence similarities with fungal ITS sequences in the family Glomeraceae.

and $98.5 \%$ similarity, respectively (Table S3).

In the flooded condition, the abundance of ASV2 and ASV4 was significantly reduced (Fig. 5). Apart from AMF, the enrichment of some fun-

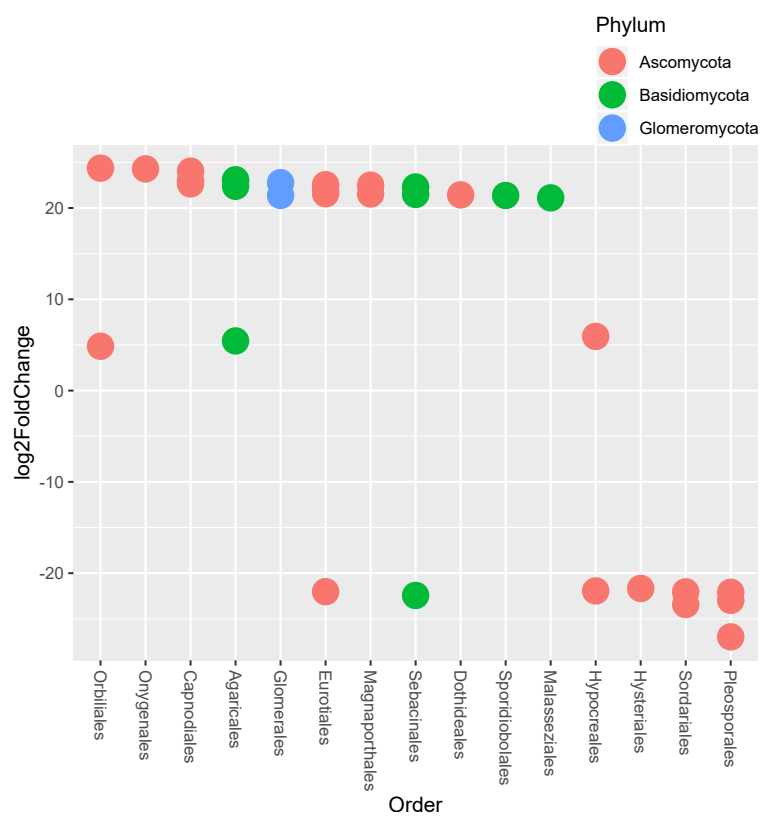

Fig. 5 Differential abundance of fungal sequence variants in rice roots under non-flooded and flooded conditions. The plot demonstrates enriched and depleted ASVs in the non-flooded versus flooded treatments.

gal ASVs in Ascomycota and Basidiomycota was markedly lower in the flooded condition whereas the abundance of some fungi in Ascomycota such as Hypocreales, Hysteriales, Sordariales and Pleosporales was significantly higher. These findings suggested that flooding also considerably affected the fungal communities and AMF abundance in the rice roots.

\section{DISCUSSION}

The soil from the organic rice paddy sampling sites was determined as P-deficient since it contained 76 ppm P without detectable available $\mathrm{P}$. This soil $\mathrm{P}$ level has been previously reported in other areas of Thailand $[28,29]$. In this experiment, the application of $\mathrm{P}$ fertilizer increased $\mathrm{Pi}$ accumulations and fresh weight of shoots and roots of rice seedlings (Fig. 1). Cytosolic Pi contents in rice seedlings were reported to vary according to environmental $\mathrm{P}$ availability [30], and reduced cytosolic Pi contents were manifested as a symptom of $\mathrm{P}$ starvation in rice plants [31]. Moreover, P deficiency in rice seedlings was reflected in reductions of shoot and root fresh weight [30]. These previous findings support the finding in this study that the addition of $\mathrm{P}$ in soil affected $P$ status in the rice seedlings.

$\mathrm{P}$ treatment inhibits AMF colonization in rice 
roots [11]. However, the application of $\mathrm{P}$ in paddy soil did not affect the intensity of AMF colonization in the rice roots in either the non-flooded or flooded condition. This result was hypothetically unexpected (Fig. 2C), but some previous studies demonstrated that $\mathrm{P}$ fertilization did not reduce AMF colonization in the host roots $[32,33]$. Perhaps, the alteration of AMF colonization might be undetectable within the short-term. It was reported that $\mathrm{P}$ enrichment of P-deficient soils did not affect AMF colonization in roots within the first year of soil $\mathrm{P}$ improvement, but differences in AMF colonization were found in the second year [34]. In addition, SMP may be P-efficient since it contains Pup1-K46, a quantitative trait locus conferring P-deficient tolerance in rice [30]. Therefore, the importance of AMF symbiosis in response to P deficiency might be attenuated in this rice variety [35].

Our data showed that AMF colonization in rice roots was inhibited by flooding (Fig. 2C). This finding is consistent with a previous study showing that flooding arrested AMF colonization while aerobic soil allowed fungi to colonize up to $80 \%$ of the roots [5]. Flooding also accelerated the formation of aerenchyma in the cortex of large lateral roots and crown roots, collapsing the accommodation for AMF [5]. In lowland rice paddies, the natural range of AMF colonization in rice roots is between 0 and $40 \%[9,10]$. This degree of AMF colonization was also detected in plant roots living in wetland habitats [8], and the same colonization levels in rice roots under flooding were induced by AMF inoculation [36]. Moreover, flooding was found to reduce but not completely block the symbiotic relationship between lowland rice and AMF [5]. In lowland rice cultivation in rain-fed areas of Southern Thailand, rice seeds are sown very early in the rainy season before the paddies become waterlogged [37]. This growing condition may enable the concurrent establishment of rice seedlings and symbiosis with AMF before the paddies are flooded in the following 2 to 4 weeks.

Fungal and AMF communities in plant roots were previously identified from general fungal ITS markers $[38,39]$. Based on ITS2 sequencing analysis, flooding changed the fungal communities and reduced AMF abundance in the studied rice roots (Fig. 3B and Fig. 5). Previous studies have shown that flooding was a crucial environmental factor that shaped fungal communities in lowland paddy soil $[5,40]$, and although microbial diversity and richness in rice roots and paddy soils are not different between lowlands and uplands, flooding significantly reduced the abundance of AMF in lowland paddy soil [15]. Additionally, similar to our findings, the abundance of Ascomycota fungi such as Hypocreales, Hysteriales, Sordariales and Pleosporales was typically enriched in the flooded condition [15] since their members are ecologically and functionally considered saprotrophic and pathogenic fungi in lowland habitats [41]. Furthermore, in lowland rice roots, the enrichment of some Ascomycetes, particularly in the genus Trichoderma, can provide the host plants with plant growth promoting substances, drought tolerance and pathogen resistance [42-44].

All the GlomASVs identified in the studied rice roots belonged to the family Glomeraceae (Fig. 4). Glomeracean AMF can be found in lowlands around the world $[9,10,15]$. In Thailand, rice paddies under conventional cultivation have been reported to contain AMF of the genus Glomus of Glomeraceae [10]. In this study, ITS2 primers were used to evaluate fungal and AMF communities. However, these primers might not be able to detect some species of AMF $[38,39]$ because of their lower sensitivity as compared to those of the Krüger set that amplifies a $1.5 \mathrm{~kb}$ SSU-ITS-LSU region, which is sufficient for AMF species identification [45].

In conclusion, our results demonstrated that although limited, lowland rice-AMF interaction can be present under anaerobic or flooded conditions. All of the detected AMF in the studied organic rice paddy soil were classified as Glomeraceae. Moreover, when the counter-effects of P deficiency and flooding on AMF colonization in rice roots were considered simultaneously, the negative impact of flooding had a more inhibiting effect on the density of native AMF colonization mainly by reducing the abundance of major AMF to colonize the rice roots.

\section{Appendix A. Supplementary data}

Supplementary data associated with this article can be found at http://dx.doi.org/10.2306/ scienceasia1513-1874.2021.025.

Acknowledgements: The authors are thankful to Phatthalung Rice Research Center, Phatthalung, Thailand, for providing soil from organic rice paddies and rice germplasms. This work was supported by a grant from Prince of Songkla University, Grant no. SCI6202028S (to L.K.) and a research assistantship from the Faculty of Science, Prince of Songkla University, Contract no. 1-2563-02-001 (to K.N.). 


\section{REFERENCES}

1. Bucher M (2007) Functional biology of plant phosphate uptake at root and mycorrhiza interfaces. New Phytol 173, 11-26.

2. Wang W, Shi J, Xie Q, Jiang Y, Yu N, Wang E (2017) Nutrient exchange and regulation in arbuscular mycorrhizal symbiosis. Mol Plant 10, 1147-1158.

3. Breuillin F, Schramm J, Hajirezaei M, Ahkami A, Favre P, Druege U, Hause B, Bucher M, et al (2010) Phosphate systemically inhibits development of arbuscular mycorrhiza in Petunia hybrida and represses genes involved in mycorrhizal functioning. Plant $J$ 64, 1002-1017.

4. Kobae Y, Ohmori Y, Saito C, Yano K, Ohtomo R, Fujiwara T (2016) Phosphate treatment strongly inhibits new arbuscule development but not the maintenance of arbuscule in mycorrhizal rice roots. Plant Physiol 171, 566-579.

5. Vallino M, Fiorilli V, Bonfante P (2014) Rice flooding negatively impacts root branching and arbuscular mycorrhizal colonization, but not fungal viability. Plant Cell Environ 37, 557-572.

6. Wang Y, Huang Y, Qiu Q, Xin G, Yang Z, Shi S (2011) Flooding greatly affects the diversity of arbuscular mycorrhizal fungi communities in the roots of wetland plants. PLoS One 6, e24512.

7. Hu S, Chen Z, Vosátka M, Vymazal J (2020) Arbuscular mycorrhizal fungi colonization and physiological functions toward wetland plants under different water regimes. Sci Total Environ 716, ID137040.

8. Xu Z, Ban Y, Jiang Y, Zhang X, Liu X (2016) Arbuscular mycorrhizal fungi in wetland habitats and their application in constructed wetland: A review. Pedosphere 26, 592-617.

9. Wang Y, Li T, Li Y, Björn LO, Rosendahl S, Olsson PA, Li S, Fu X (2015) Community dynamics of arbuscular mycorrhizal fungi in high-input and intensively irrigated rice cultivation systems. Appl Environ Microbiol 81, 2958-2965.

10. Watanarojanaporn N, Boonkerd N, Tittabutr P, Longtonglang A, Young JPW, Teaumroong N (2013) Effect of rice cultivation systems on indigenous arbuscular mycorrhizal fungal community structure. Microbes Environ 28, 316-324.

11. Hajiboland R, Aliasgharzad N, Barzeghar R (2009) Phosphorus mobilization and uptake in mycorrhizal rice (Oryza sativa L.) plants under flooded and nonflooded conditions. Acta Agric Slov 2, 153-161.

12. Zhang S, Guo X, Yun W, Xia Y, You Z, Rillig MC (2020) Arbuscular mycorrhiza contributes to the control of phosphorus loss in paddy fields. Plant Soil 447, 623-636.

13. Hérique O, Faysse N (2020) A large-scale public programme to promote organic rice farming in Thailand: building solid foundations to enable farmers to engage? Org Agric.
14. Suwanmaneepong S, Kerdsriserm C, Lepcha N, Cavite HJ, Llones CA (2020) Cost and return analysis of organic and conventional rice production in Chachoengsao Province, Thailand. Org Agric 10, 369-378.

15. Chialva M, Ghignone S, Cozzi P, Lazzari B, Bonfante P, Abbruscato P, Lumini E (2020) Water management and phenology influence the root-associated rice field microbiota. FEMS Microbiol Ecol 96, ID fiaa146.

16. Xavier Martins WF, Rodrigues BF (2020) Identification of dominant arbuscular mycorrhizal fungi in different rice ecosystems. Agric Res 9, 46-55.

17. AOAC International (2016) Fertilizers. In: Kane PF (ed) Official Methods of Analysis of AOAC International, 20th edn, AOAC International, Maryland, USA, pp 1-60.

18. Hurry V, Strand A, Furbank R, Stitt M (2000) The role of inorganic phosphate in the development of freezing tolerance and the acclimatization of photosynthesis to low temperature is revealed by the pho mutants of Arabidopsis thaliana. Plant $J$ 24, 383-396.

19. Dellaporta SL, Wood J, Hicks JB (1983) A plant DNA minipreparation: Version II. Plant Mol Biol Report 1, 19-21.

20. Callahan BJ, McMurdie PJ, Rosen MJ, Han AW, Johnson AJA, Holmes SP (2016) DADA2: High-resolution sample inference from Illumina amplicon data. Nat Methods 13, 581-583.

21. Bolyen E, Rideout JR, Dillon MR, Bokulich NA, Abnet CC, Al-Ghalith GA, Alexander H, Alm EJ, et al (2019) Reproducible, interactive, scalable and extensible microbiome data science using QIIME 2. Nat Biotechnol 37, 852-857.

22. Nilsson RH, Larsson K-H, Taylor AFS, BengtssonPalme J, Jeppesen TS, Schigel D, Kennedy P, Picard $\mathrm{K}$, et al (2019) The UNITE database for molecular identification of fungi: handling dark taxa and parallel taxonomic classifications. Nucleic Acids Res 47, 259-264.

23. McMurdie PJ, Holmes S (2013) phyloseq: An R package for reproducible interactive analysis and graphics of microbiome census data. PLoS One 8, e61217.

24. Oksanen J, Blanchet FG, Kindt R, Legendre P, Minchin P, O'Hara RB, Simpson G, Solymos P, et al (2018) Vegan: Community Ecology Package, R Package Ver2.4-6.

25. Love MI, Huber W, Anders S (2014) Moderated estimation of fold change and dispersion for RNA-seq data with DESeq2. Genome Biol 15, ID 550.

26. Wickham H (2016) Ggplot2: Elegant Graphics for Data Analysis, Springer International Publishing.

27. Mendiburu FD (2015) Agricolae: Statistical procedures for agricultural research. $R$ Package Version 1.23. Available at: http://cran.r-project.org/package $=$ agricolae. 
28. Uwasawa M, Sangtong P, Cholitkul W (1988) Behavior of phosphorus in paddy soils of Thailand. Soil Sci Plant Nutr 34, 41-53.

29. Phairat P, Toru M (2003) The status of phosphorus in Thai soils and P evaluation using EDTA-NaF extraction method. Songklanakarin J Sci Technol 25, 423-434.

30. Klinnawee L, Sok B, Duangpan S, Meesawat U (2020) Pup1-K46 fosters internal phosphorus accumulation in lowland indica rice. Asian J Plant Sci 19, 205-213.

31. Zhong Y, Wang Y, Guo J, Zhu X, Shi J, He Q, Liu Y, Wu Y, et al (2018) Rice SPX6 negatively regulates the phosphate starvation response through suppression of the transcription factor PHR2. New Phytol 219, 135-148.

32. Liang J-F, An J, Gao J-Q, Zhang X-Y, Yu F-H (2018) Effects of arbuscular mycorrhizal fungi and soil nutrient addition on the growth of Phragmites australis under different drying-rewetting cycles. PLoS One 13, e0191999.

33. Higo M, Azuma M, Kamiyoshihara Y, Kanda A, Tatewaki Y, Isobe K (2020) Impact of phosphorus fertilization on tomato growth and arbuscular mycorrhizal fungal communities. Microorganisms 8, 178.

34. Higo M, Sato R, Serizawa A, Takahashi Y, Gunji K, Tatewaki Y, Isobe K (2018) Can phosphorus application and cover cropping alter arbuscular mycorrhizal fungal communities and soybean performance after a five-year phosphorus-unfertilized crop rotational system? PeerJ 6, e4606-e4606.

35. Wissuwa M, Ae N (2001) Further characterization of two QTLs that increase phosphorus uptake of rice (Oryza sativa L.) under phosphorus deficiency. Plant Soil 237, 275-286.

36. Secilia J, Bagyaraj DJ (1994) Selection of efficient vesicular-arbuscular mycorrhizal fungi for wetland rice-a preliminary screen. Mycorrhiza 4, 265-268.

37. Zeigler RS, Puckridge DW (1995) Improving sustainable productivity in rice-based rainfed lowland systems of south and southeast Asia. GeoJournal 35, 307-324.
38. Kohout P, Sudová R, Janoušková M, Čtvrtláková M, Hejda M, Pánková H, Slavíková R, Štajerová K, et al (2014) Comparison of commonly used primer sets for evaluating arbuscular mycorrhizal fungal communities: Is there a universal solution? Soil Biol Biochem 68, 482-493.

39. Lekberg Y, Vasar M, Bullington LS, Sepp S-K, Antunes PM, Bunn R, Larkin BG, Öpik M (2018) More bang for the buck? Can arbuscular mycorrhizal fungal communities be characterized adequately alongside other fungi using general fungal primers? New Phytol 220, 971-976.

40. Solaiman MZ, Hirata H (1997) Effect of arbuscular mycorrhizal fungi inoculation of rice seedlings at the nursery stage upon performance in the paddy field and greenhouse. Plant Soil 191, 1-12.

41. Robinson SJB, Elias D, Johnson D, Both S, Riutta T, Goodall T, Majalap N, McNamara NP, et al (2020) Soil fungal community characteristics and mycelial production across a disturbance gradient in lowland dipterocarp rainforest in Borneo. Front For Glob Chang 3, ID 64.

42. Doni F, Zain CRCM, Isahak A, Fathurrahman F, Sulaiman N, Uphoff N, Yusoff WMW (2017) Relationships observed between Trichoderma inoculation and characteristics of rice grown under System of Rice Intensification (SRI) vs. conventional methods of cultivation. Symbiosis 72, 45-59.

43. de França SKS, Cardoso AF, Lustosa DC, Ramos EMLS, de Filippi MCC, da Silva GB (2015) Biocontrol of sheath blight by Trichoderma asperellum in tropical lowland rice. Agron Sustain Dev 35, 317-324.

44. Shukla N, Awasthi RP, Rawat L, Kumar J (2012) Biochemical and physiological responses of rice (Oryza sativa L.) as influenced by Trichoderma harzianum under drought stress. Plant Physiol Biochem PPB 54, 78-88.

45. Krüger $M$, Krüger $C$, Walker $C$, Stockinger $H$, Schüßler A (2012) Phylogenetic reference data for systematics and phylotaxonomy of arbuscular mycorrhizal fungi from phylum to species level. New Phytol 193, 970-984. 


\section{Appendix A. Supplementary data}
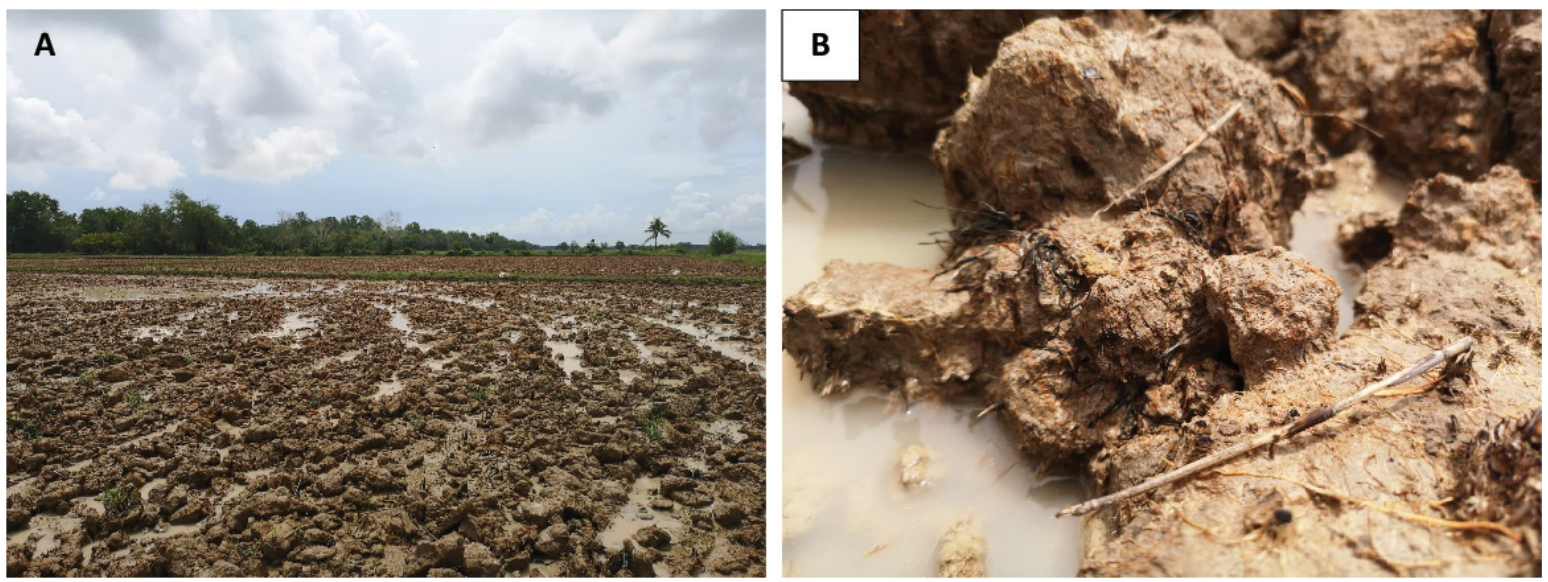

Fig. S1 Soil sampling. (A) The soil was randomly collected in organic rice paddies immediately after plowing. (B) The soil contained rice roots from previous rice cultivation.

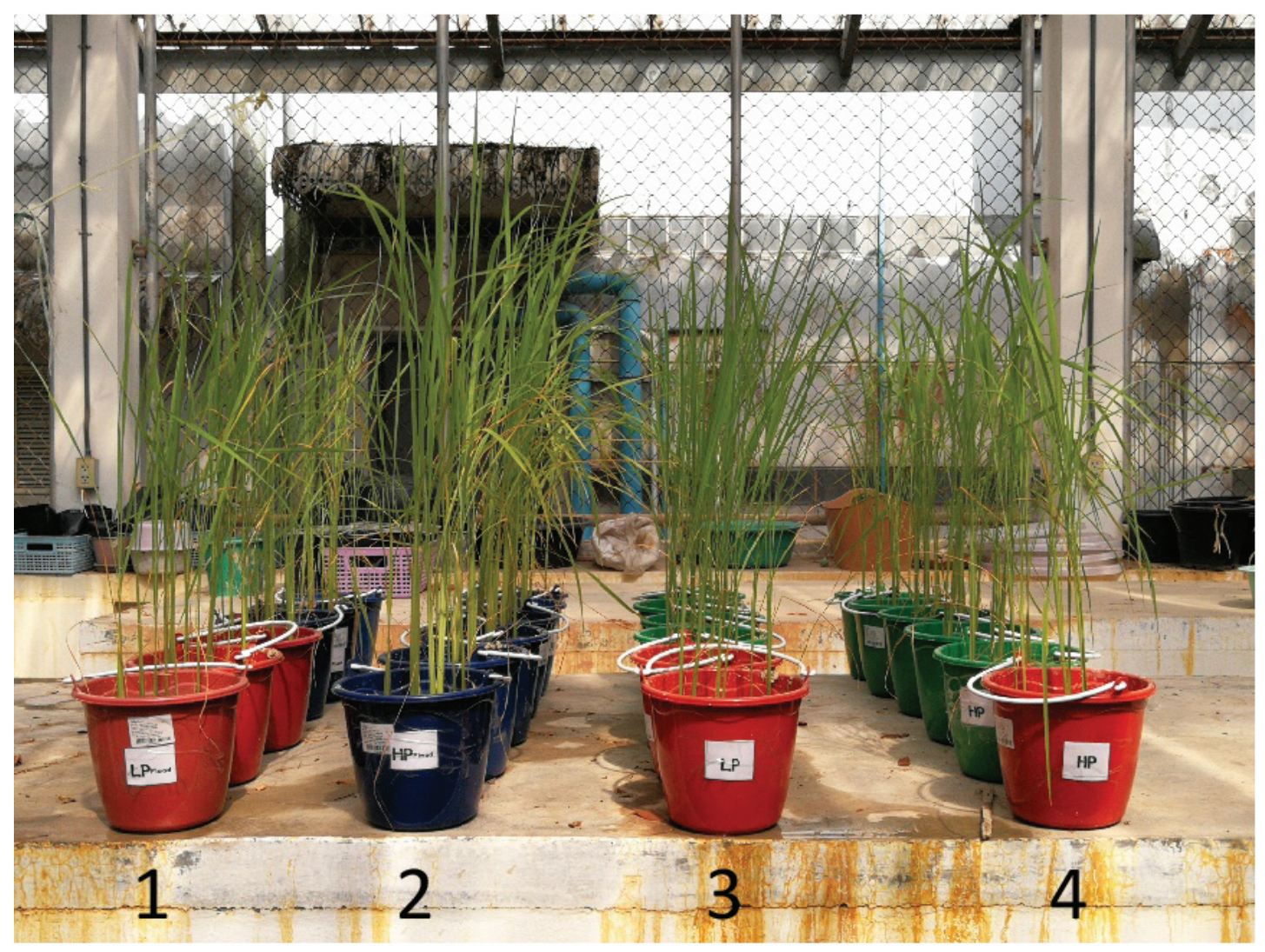

Fig. S2 Rice seedlings under different $\mathrm{P}$ and water availability. Two-week old seedlings were treated with low and high levels of $\mathrm{P}$ under flooded and non-flooded conditions for 4 weeks. Therefore, in this experiment, there were 4 different growing conditions: (1) low P and flooded, (2) high P and flooded, (3) low P and non-flooded and (4) high $\mathrm{P}$ and non-flooded. Each treatment contained 6 pots ( $n=6$ biological replicates). 
Table S1 Comparison of shoot and root Pi accumulations, shoot and root fresh weight and AMF colonization rate of plants at 2, 4 and 6 weeks after treatment under non-flooded and flooded conditions with and without P fertilization. Comparison was performed by three-way ANOVA $(p<0.05)$.

\begin{tabular}{lccccccc}
\hline Parameter & \multicolumn{7}{c}{ Source of variance } \\
\cline { 2 - 8 } & Week (W) & Flooding (F) & Phosphorus (P) & $\mathrm{W} \times \mathrm{F}$ & $\mathrm{W} \times \mathrm{P}$ & $\mathrm{F} \times \mathrm{P}$ & $\mathrm{W} \times \mathrm{F} \times \mathrm{P}$ \\
\hline shoot Pi content & $*$ & $*$ & $*$ & n.s. & $*$ & n.s. & n.s. \\
root Pi content & $*$ & $*$ & $*$ & $*$ & n.s. & n.s. & n.s. \\
shoot fresh weight & $*$ & $*$ & $*$ & $*$ & $*$ & n.s. & n.s. \\
root fresh weight & $*$ & $*$ & $*$ & $*$ & $*$ & n.s. & n.s. \\
AMF colonization & $*$ & $*$ & n.s. & $*$ & n.s. & n.s. & $*$ \\
\hline
\end{tabular}

${ }^{*} p<0.05$, n.s. $=$ not significant at $p<0.05$.

Table S2 Comparison of fungal communities in rice roots grown under different water and phosphorus availabilities. Comparison was performed by pair-wise PERMANOVA of Bray-Curtis distances.

\begin{tabular}{lcc}
\hline Comparison & $R^{2}$ & $p$-value \\
\hline flooding vs. non-flooding & 0.14505 & 0.038 \\
high phosphorus vs. low phosphorus & 0.11570 & 0.164 \\
high phosphorus and non-flooding vs. low phosphorus and non-flooding & 0.20796 & 0.5 \\
high phosphorus and flooding vs. low phosphorus and flooding & 0.23532 & 0.2 \\
high phosphorus and non-flooding vs. high phosphorus and flooding & 0.32974 & 0.1 \\
low phosphorus and non-flooding vs. low phosphorus and flooding & 0.19345 & 0.6 \\
\hline
\end{tabular}

Table S3 Species hypotheses by UNITE.

\begin{tabular}{lllcc}
\hline GlomASV & Reference & Taxon name & \% Identity & $E$-value \\
\hline 1 & KM208429 & Glomeraceae (Rhizophagus clarus) & 100.00 & $2.61 \mathrm{E}-55$ \\
2 & KM208092 & Glomeraceae & 97.10 & $3.11 \mathrm{E}-93$ \\
3 & FR873160 & Glomeraceae & 94.84 & $3.49 \mathrm{E}-88$ \\
4 & FR873160 & Glomeraceae & 94.88 & $2.70 \mathrm{E}-89$ \\
5 & KM208068 & Glomeraceae & 99.03 & $1.87 \mathrm{E}-100$ \\
6 & KM208084 & Glomeraceae & 98.06 & $1.44 \mathrm{E}-96$ \\
7 & KM208354 & Glomeraceae (Rhizophagus clarus) & 98.56 & $1.27 \mathrm{E}-102$ \\
8 & KM208092 & Glomeraceae & 97.12 & $8.76 \mathrm{E}-94$ \\
\hline
\end{tabular}

